\title{
THE JANUS EFFECT: CONTRADICTORY DEMANDS PLACED ON THE ACADEMIC CHAIRPERSON
}

\author{
J. W. Pienaar \\ Department of Industrial Psychology \\ University of the Free State \\ Bloemfontein, South Africa \\ e-mail: southafrica@arbinger.co.za

\section{F. Cilliers} \\ Department of Industrial and Organisational Psychology \\ University of South Africa \\ Pretoria, South Africa \\ e-mail: cillifvn@unisa.ac.za
}

\section{ABSTRACT}

The purpose of this article is to gain a deeper understanding of the multidimensional nature and complexity of the challenges academic chairpersons appointed at institutions of higher learning experience. A qualitative research approach was chosen to gain a comprehensive understanding of the phenomenon under investigation by means of a focus group of 24 academic chairpersons. The findings indicate that academic chairpersons are inundated with responsibilities. They have to find a balance between the various roles, responsibilities and tasks originating from two opposing roles - that of scholar versus that of administrator/manager/leader - forced into one, while lacking the necessary administrative/managerial/leadership experience, skills and knowledge for their role as managers. This study provides higher education institutions and roleplayers responsible for the appointment, support and development of academic chairpersons with the evidence required to substantiate the necessity of redesigning this role.

Keywords: academic chairpersons, challenges of academic chairpersons, roles of academic chairpersons, higher education, academic leadership, chairperson demands

\section{INTRODUCTION}

The effective functioning of higher education institutions may be in jeopardy if the role of the academic chairperson is not revised or reconceptualised in the near future. The role of an academic chairperson is considered to be one of the key positions at institutions of higher learning (Aziz, Mullins, Balzer, Grauer, Burnfield, Lodato and Cohen-Powless 2005, 572; Czech and Forward 2010, 431; Gmelch and Burns 1994, 80; London 2011, 37; Sotirakou 2004, 351; Spiller 2010, 680; Wescott 2000, 1), while Hecht $(2004,5)$ indicates that institutions of 
higher learning will come to depend even more on the effectiveness of academic chairpersons in the future. The chairperson of an academic department not only plays an important role in the academic leadership of an institution, but also makes up to 80 per cent of all the administrative decisions made in universities (Carroll and Wolverton 2004, 3). In 1997 alone, 80000 academic chairpersons were appointed in higher education settings worldwide, and it is estimated that one to three out of all academics will eventually serve in this role at some point in time in their careers (Wescott 2000, 2).

Buffone (2009, 18), Deem (2004) (as cited in Floyd 2012, 273), Gmelch and Burns (1993, 259), Spiller (2010, 680) as well as Stanley and Algert $(2007,50)$ assert that the role of the academic chairperson represents one of the most challenging, uniquely stressful and complex roles, without any common management parallels. The complexity of this role is depicted by Gmelch and Burns $(1994,79)$, who draw on imagery from the god Janus in Roman mythology. According to the mythology Janus had two faces: one face was turned to the front and the other to the back. Academic chairpersons may very well hold the same stance; one face represents the role of administrator/manager/leader and the other that of academic faculty member. This will here be referred to as the Janus effect. Chairpersons therefore take up the classic personin-the-middle role, where they are required to drive the responsibilities bestowed upon them by an institution on the one hand, while on the other hand managing an academic career that is tied firmly to an academic department. Understandably they are in a constant struggle to find a balance between the tasks and responsibilities associated with their administrative/managerial/leadership role and those of being an academic.

The question regarding the sustainability of the role of academic chairperson, however, becomes clear when one considers the magnitude of tasks and responsibilities chairpersons need to contend with, as reflected in a study by a research team from the University of Nebraska, (as cited in Gmelch and Miskin 1993, 6) who listed 97 activities associated with the role of an academic chairperson. Allan Tucker, in his book Chairing the academic department, identified 54 varieties of tasks and duties associated with this role (Gmelch and Miskin 1993, 6). Potgieter, Basson and Coetzee $(2011,87)$ identified 40 managerial competencies necessary to function effectively as an academic chairperson. What is worrisome is Brynman's $(2009,6)$ belief that the tasks and responsibilities of this role will increase in the future. It is therefore not surprising to find that chairing an academic department is considered one of the most difficult and stressful roles at institutions of higher education (Aziz et al. 2005, 572; King 1997, 211; Wescott 2000, 1).

The following selection from the literature will endeavour to provide a précis on some of 
the more prominent realities, complexities and challenges associated with the role of an academic chairperson. This will bring a deeper understanding of its multidimensional nature.

\section{SERVING DIFFERENT 'MASTERS'}

On the one hand a chairperson needs to contend with the responsibilities of being an academic, which involves serving the three pillars of teaching, research and community engagement; roles that operate in a more free and independently coupled system. On the other hand, a chairperson fulfils the role of administrator/manager/leader, a role that requires operating within the mechanistic qualities of a tightly managed institutional system. The chairperson, primarily responsible for balancing, containing and mediating the inherent realities, responsibilities and demands associated with his or her conflicting roles is therefore likely to endure the demands of someone who must please different 'masters' (Carroll and Wolverton 2004, 6-7; Floyd 2012, 273; Gmelch 2004, 4, 75; Gmelch and Burns 1993, 260; Gmelch and Burns 1994, 80; Gmelch and Miskin 1993, 11; Sotirakou 2004, 350; Stanley and Algert 2007, 53; Wescott 2000, 2; Wolverton, Ackerman and Holt 2005, 229). The pressure of this role will mount as various constituencies within higher education (administration and academic staff) expect academic chairs to be role-model academics and leaders (Hecht, Higgerson, Gmelch and Tucker 1999, 1, 3).

\section{THE IMPROMPTU ADMINISTRATOR/MANAGER/LEADER}

Institutions are, however, more dependent than ever on chairpersons possessing superb managerial skills - chairs who are well able to implement university policies and directives, and affect change in order to assist institutions reaching their objectives amidst all the internal and external challenges (Hecht et al. 1999, 1-17). A chairperson therefore often, if not daily, faces numerous administrative and managerial responsibilities and activities in the form of budgeting, campus governance, staff matters, faculty hiring and evaluation, monitoring of standards, promoting racial and gender balance, encouraging continued personal and professional growth, attesting to the adequacy of instruction and research (Lyons 2008, 392393; Wescott 2000, 2, 4), preparing strategic plans, mediating conflicts (Aziz et al. 2005, 572) and establishing and maintaining departmental cultures (Carroll and Wolverton 2004, 3; Wolverton et al. 2005, 228), to name but a few. This balancing act between being an academic and an administrator/manager/leader becomes problematic when considering that chairpersons are rarely prepared for the tasks associated with the latter role (Potgieter and Coetzee 2010, 9). This situation is aggravated by chairpersons who originate from disciplines not familiar with 
administration, management or leadership (Hecht et al. 1999, 4; Wescott 2000, 3).

According to Tucker (as cited in King 1997, 211), less than one third of new academic chairpersons have the necessary administrative experience or the necessary management experience to qualify them for this position (Carroll and Wolverton 2004, 8). The problematic nature of this role is further exacerbated when considering the research by Gmelch (as cited in Wolverton et al. 2005, 227), who has shown that only 3 per cent of 2000 academic leaders surveyed in the US from 1990 to 2000 had any type of leadership preparation. The reason for this, according to Gmelch (as cited in Buffone 2009, 9), is that many institutions do not view leadership as an important or necessary skill for faculty members. This might provide an explanation why institutions of higher learning mainly elect or instate chairpersons based on their academic achievements as scholars, and not necessarily on their skills, knowledge and experience as administrators/managers/leaders (Bennett as cited in Lyons 2008, 58). This lack of foresight is echoed in the words of Hecht et al. $(1999,7)$, who state that '[i]t is ludicrous to hire someone to deal with complex process without empowering and training them to deal with all these complex issues’. Graham and Benoit (2004, 1), Hecht et al. (1999, 1) and Potgieter and Coetzee $(2010,9)$ are of the opinion that the role of administrator/manager/leader requires a different set of skills and talents from a chairperson, compared to what is required of an academic. The problematic nature of this role is further exacerbated by the mental shift that a chairperson also needs to make from functioning as an individual academic to managing a collective who works independently, while lacking the necessary skills, knowledge and experience (Hecht et al. 1999, 12-13, 16).

\section{RELATIONSHIP MANAGEMENT}

To add to the paradoxical nature and complexity associated with the role of academic chairperson, Hecht et al. $(1999,2)$ state that 'departmental chairs are the only academic managers who must live with their decisions every day'. Deans and other administrative leaders, who normally have to contend with issues such as operating budgets, rarely have to worry about maintaining intimate relationships; a chair on the other hand needs to maintain and contain an intimate relationship with staff members (almost like a family) - a relationship that is not duplicated anywhere else within institutions of higher education. Contrary to administrative leaders in higher education institutions, it is not uncommon for a chairperson to be aware of each staff member's 'vital statistics' (births, deaths, marriages, divorces, illnesses and financial woes). This is because they are bound together in many ways (they teach together, they often have similar values - personally and in their discipline - and share professional 
backgrounds, goals and interests). It is the academic chairperson who needs to manage this connectedness in order to keep the peace for the sake of mutual benefit and progress (Hecht et al. 1999, 1).

King (1997, 212) states that the role of colleague and friend are every so often compromised by the responsibilities chairs have to carry out in the form of evaluations and the allocation of scarce resources and rewards; aspects that might complicate the interpersonal relations, while research indicates that maintaining positive relationships are essential for academic chairpersons managing departments. The importance of establishing and maintaining a collegial working environment is supported by a study by Scott, Coated and Anderson (2008) (as cited in Spiller 2010, 680), who identified this as one of the five key areas in a study of 513 academic leaders. The opposite is also true, in that a chairperson's effectiveness may be compromised because they need to be highly collegial, otherwise it could be very difficult for them when they return to their faculty position, which is often the case (Rowley and Sherman 2003, 1058). Chairpersons therefore constantly have to move between respect for faculty autonomy and the responsibility to carry out departmental and institutional missions (Hecht et al. 1999, 5). It may well be that chairpersons have no other leverage than to manage by relationship. Literature shows that academic chairpersons often lack the power and/or authority to carry out many of these delegated responsibilities and assumed duties, as this role is somewhere between the faculty and the administration and often lacks formal and positional authority (Hecht et al. 1999, 12-13 and 16; King 1997, 212).

\section{PROBLEM STATEMENT}

Although the above literature (also see Gmelch and Burns 1993, 259; 1994, 80, 91; Gmelch and Miskin 1993, 2) suggests that the academic chairperson plays a pivotal role in the effective functioning of any higher education institution, there are very few researchers, according to Sotirakou (2004, 350), who venture into studying this multidimensional role, and when research is done, it is often of an anecdotal nature. This is especially true for academic chairpersons employed at institutions of higher learning in South Africa, as there is little apparent research available exploring the challenges they face in a developing country such as South Africa.

The necessity to gain a deeper understanding of the multidimensional nature, complexity and challenges associated with this role is echoed by Buffone $(2009,16,18)$ and Hecht et al. $(1999,14)$, and reflected in the words of Berdrow $(2010,500)$, who states that ' $[t]$ his role far exceeds the due it is given'. This need is further corroborated by Gmelch (as cited in Buffone 2009, 200), who states that ' $[\mathrm{t}$ ]he academic leader is the least studied and most misunderstood 
management position'. In the absence of studies focusing on this role, higher education will continue to experience 'leadership crises' (Gmelch and Burns 1993, 265) and will be unable to develop practices and programmes on how to prepare academic chairpersons for this role (Buffone 2009, 16) or provide them with the necessary support (Hecht et al. 1999, 7).

Gmelch and Burns $(1994,83)$ also highlight that research should not be limited to generic sources of stress or challenges in the hope of gaining a deep understanding, but that it may be necessary to consider all challenges that are unique to a particular profession or role in this case. Although instruments would be able to examine general stress or challenges, they are inadequate when investigating a multidimensional role of this nature. Berdrow $(2010,499)$ and Lyons $(2008,73)$ state that the role of academic chairpersons should be studied within the context (time, space, culture and other contexts) of a particular organisation (higher education institution) as a system in order to obtain a more in-depth understanding of the aspects affecting this role. For this reason, the authors of the article employed a qualitative approach to identify and gain a deeper understanding of the challenges faced by academic chairpersons at a specific institution.

\section{RESEARCH METHODOLOGY}

A qualitative approach was chosen to gain a comprehensive understanding of the experiences of the participants and the phenomena under investigation (De Vos, Strydom, Fouché and Delport 2002, 333-359). The aim was to describe the phenomena, rather than working with pre-conceived ideas about the phenomena (Zaharlick 1992, 118, 121). To put it differently, the aim was to focus on observing, describing and interpreting the way that people experience, act on, or think about themselves within a specific context (Bazeley 2013, 4).

\section{Research sample and research setting}

The sample consisted of 24 academic chairpersons from various academic departments appointed at a medium-sized South African higher education institution.

\section{Sampling method and procedure}

A convenience sampling method (Breverton and Millward 2004, 114-121) was used to collect the data. An e-mail invitation was forwarded by the representative of the university tasked with the development of academic chairpersons to all of the academic chairpersons $(\mathrm{N}=98)$ at the particular institution, one month prior to the envisaged discussion. They were notified of and invited to a discussion of their particular challenges as chairpersons of academic departments. 
All the participants were informed about the rationale, method and logistics of the event (the data-collection discussion), by way of the invitation to the event and again on the day of the event. In the invitation, participants were also given an opportunity to decide whether they would prefer to attend the session in Afrikaans or English. Participants thus had an opportunity to attend the session in one of the two official languages of the institution and in the language of their choice. They were therefore divided into two groups: those attending the event conducted in Afrikaans and those who would attend the English event.

Twenty-four academic chairpersons, a group consisting of 14 men and 10 women, attended the two sessions. This group represented 23 per cent of the academic chairpersons at the university. All of the participants declared themselves willing to participate in the discussion and gave consent that the data may be utilised for research purposes.

\section{Method of data collection}

Focus groups were used as the method for collecting the data. A focus group is essentially a group discussion focused on a particular theme or topic (Berg 2001, 111; Wilkinson 2011, 168), where multiple individuals can simultaneously be interviewed (Berg 2001, 111; Boateng 2012, 54). The goal of a focus group, according to Stewart, Shamdasani and Rook $(2007,9)$, is to 'gather qualitative data from individuals who have experienced some "particular concrete situation”'. Kreuger and Casey $(2009,2,6,8)$ provide various uses of focus groups that are aligned with the purpose of this research. These are to (a) bring forth a range of feelings, opinions and ideas; (b) understand differences in perspective; and (c) seek ideas that might emerge because of the social interaction. It must also be acknowledged that focus groups, while serving a useful function, are not without their own limitations. In light of the purpose of the study the advantages associated with this method as indicated in various literature (Berg 2001, 111-112, 114-120; Boateng 2012, 54-56; Onwuegbuzie, Dickinson, Leech and Zoran 2009, 2) outweigh the disadvantages.

Both researchers took up the role of convenor/moderator during the two focus group engagements by managing the time (two hours was allowed for the event) and the task boundaries (which was stated as 'to reflect and explore with one another your specific challenges as an academic chairperson at this university'), as indicated in Onwuegbuzie et al. $(2009,4)$.

The engagement was semi-structured in that it allowed space for two hours to explore the specific question at hand through thinking and free-associating, thereby providing participants with an opportunity to share thoughts with one another and to discuss the aspects and challenges 
most pressing for them at that moment in their role as academic chairpersons (Berg 2001, 111112; Onwuegbuzie et al. 2009, 2-3). Furthermore, all the sessions were recorded electronically, transcribed and kept safe for the data analysis process, which will be described in the next section.

\section{Method of data analysis}

Thematic analysis was used to conduct the qualitative analysis of the data, as it is an acceptable way to identify, analyse and report data patterns according to Wilkinson $(2011,169)$. Braun and Clarke’s (2006, 87-93) framework was used, as it comprises six distinguishable phases:

Phase 1: The researcher familiarised himself with the data (data were transcribed, read, re-read, and the most prominent ideas were noted).

Phase 2: Criteria were systematically coded by using the entire dataset, collating data relevant to each code.

Phase 3: Codes were collated into potential themes, by gathering all data applicable to each theme.

Phase 4: Themes were reviewed to see if they work in relation to the coded extracts (Level 1) and the entire data set (Level 2).

Phase 5: Themes were defined and named in an endeavour to ensure ongoing analysis, and to refine the specifics of each theme, in light of the overall story of the analysis. Thereby specific definitions and names for each theme were generated.

Phase 6: The report was produced by selecting illustrative examples of responses that provide evidence, and relating the examples back to the research question and existing literature so as to confirm the final analysis. Making use of as many verbatim excerpts as possible was another way for the researcher to support the credibility of the analytical claims.

\section{Strategies employed to ensure quality data}

Scientific rigour was ensured by focusing on credibility, dependability, validity and ethics (Terre Blanche, Durrheim and Painter 2006, 59-64). Credibility was ensured by the authorised involvement of all parties (Hirschhorn 1997, 9-25). Dependability was ensured by the scientific rigour applied in the planning and execution of the research project. The credibility and validity of the data were increased by both researchers performing independent data analyses and by creating a contained space without judgement or desire to influence the outcome of the discussions during the data gathering engagements. Another process that was followed to 
increase the credibility and validity of the data was sharing the preliminary results with all the participants, giving them an opportunity to respond before the results were finalised. Ethicality was achieved by obtaining informed consent from all participants, by voluntary participation, and by keeping the identities of the participants confidential and not causing harm to or invading any person’s privacy, as indicated by De Vos, Strydom, Fouche and Delport (2002, 67-70).

\section{FINDINGS AND DISCUSSION}

The data analysis revealed multiple challenges that are structured around three major themes as depicted in Figure 1, namely challenges inherent to the role of an academic chairperson, contextual challenges (unexpected external aspects that might affect the role of the chairperson) and the consequences of these challenges, which could also be postulated as challenges. These themes will be

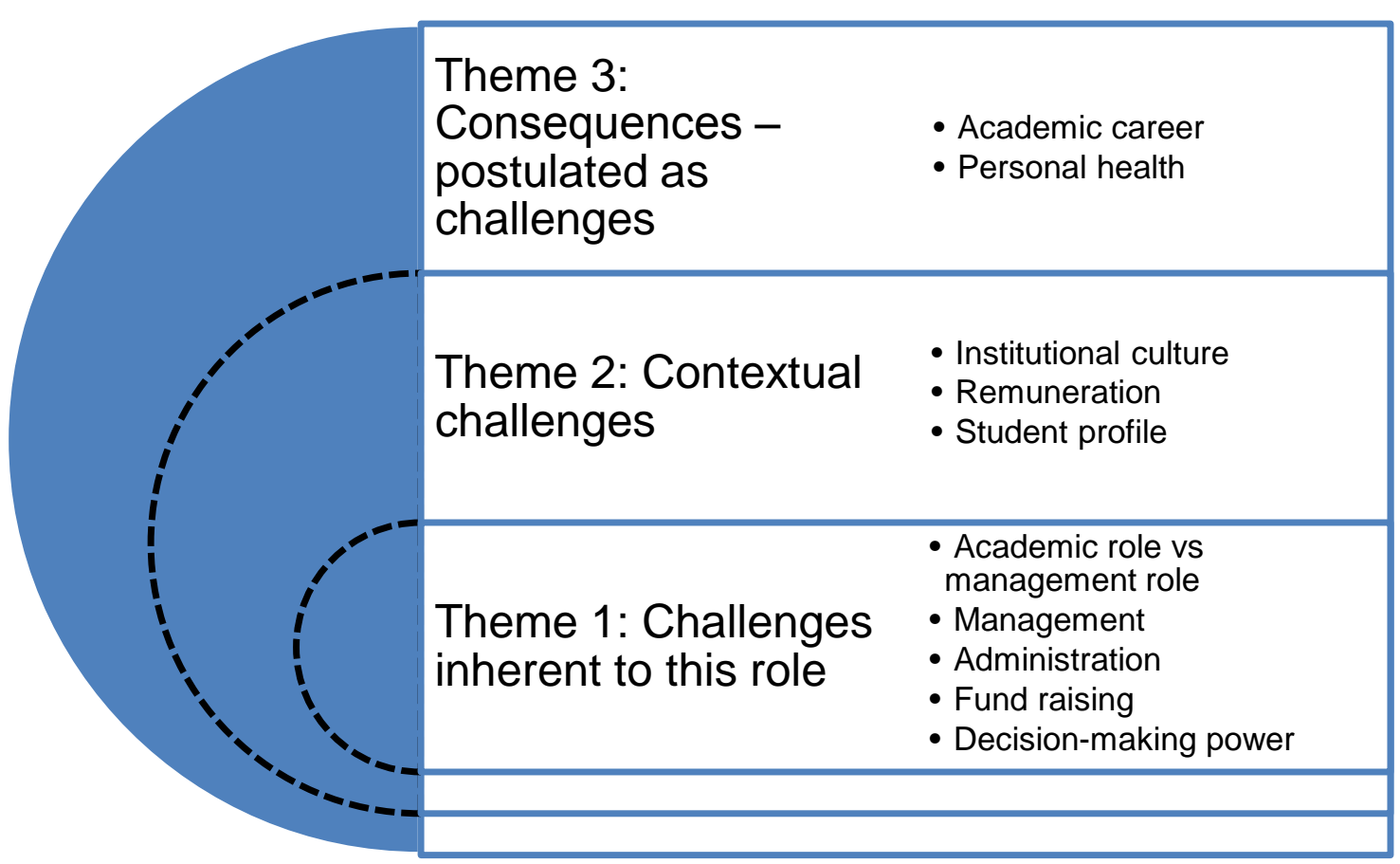

Figure 1: Multiple challenges experienced by academic chairpersons

\section{Challenges inherent to the role of academic chairperson (Theme 1)}

The findings of this study as depicted in this theme demonstrate that academic chairpersons struggle to find a balance between their tasks and responsibilities of being an academic on the one hand and that of being an administrator/manager/leader on the other hand. It seems that the majority of challenges for academic chairpersons stems from their role as administrator/manager/leader. The following sub-themes will highlight these challenges in 
more detail.

\section{Academic role versus management role}

There seems to be a general consensus among chairpersons in the study that they find it particularly difficult to find a balance between the above two roles, as indicated by various comments made by participants. One such a statement, for example, was 'I find it difficult to distinguish between the different roles and responsibilities associated with that of an academic chairperson'. Role overload and role confusion seem to characterise the role of chairperson, as corroborated by comments such as 'My workload is 204\% at this stage' and 'I cannot lecture, do research and be a good chairperson at the same time'. Such experiences are verified by Carroll and Wolverton (2004, 6-7), Gmelch and Burns (1993, 260; 1994, 80), Gmelch and Miskin $(1993,11)$ and Wescott $(2000,2,4)$, who, as stated earlier in this article, argues that the role of a chairperson entails balancing, containing and mediating the inherent realities, responsibilities and demands of two opposing roles, much as depicted by the image of the twofaced god Janus in Roman mythology, referred to as the Janus effect in this article. There is likely to be a compounding effect in this role when considering the comment that ' $[t]$ op management is always adding 'things' to my role', and is in many instances amplified in this particular institution when considering comments such as ' $[\mathrm{m}] \mathrm{y}$ management responsibilities also extend to other satellite campuses' (campuses that are physically removed from their main campus responsibilities).

This compounding effect is supported by Sotirakou (2004, 349), who asserts that all institutions are under pressure to increase the scope of their offering. As a result, more and more responsibilities are delegated to academic chairpersons. Buffone $(2009,18)$ shares the same sentiment when indicating that chairs have such wide-ranging roles and responsibilities that it is difficult to quantify them comprehensively. The aforementioned is confirmed in research by Giles-Gee and McMahon (as cited in Aziz et al. 2005, 574), who indicate that 79 per cent of academic chairpersons in a study experienced that their work increased. In studies among chairpersons by Gmelch (as cited in Lyons 2008, 134), it was found that chairs who reported excessive stress indicated that 70 per cent of this could be attributed to their attempting to balance their roles as both academic and administrator/manager/leader. Wolverton et al. (2005, 230) have shown in research with 56 academic chairpersons that three main themes always surface, of which balancing roles is one. The other two, namely budgetary issues and personnel management, surfaced in the current study as well, as will be illustrated in the subsequent themes. These issues will necessarily have a compounding effect on the workload and time 
commitments of academic chairpersons as demonstrated in the findings of this study and the associated comments elsewhere.

\section{Management}

It seems that the most prominent challenges faced by academic chairpersons stem from their management role and more specifically from matters related to financial and human resources. So, for example, chairpersons indicated that they were ill-prepared to manage the financial matters of a department. One participant mentioned '[y]ou feel supported, in would you like some more coffee, but not in the sense of what to do, where to do it and where to get the basic stuff; how to create an entity, how to manage an entity - those things'. It seems that it is especially the various facets within the realm of human resource management that pose some of the biggest challenges. Some of the more prominent aspects mentioned by chairpersons are linked to the management of interpersonal relationships and the conflict between colleagues (academics), as corroborated by the following statements: 'As a departmental chair there are many instances that you need to manage the conflict between personnel and between personnel and students', 'The issue around managing conflict is a real challenge' and 'It is the people issues'.

Chairpersons are very unlikely and reluctant to intervene in personnel matters of this nature because they attach a high priority to their collegial relationships, making them reluctant to tackle sensitive issues that may harm those relationships. As mentioned earlier, this might be because they may very well need to return to the same academic department as a colleague when their term as chairperson comes to an end and that they therefore do not want to create any animosity or ill feelings (Hecht, Higgerson, Gmelch and Tucker 1995, 5). Another reason for this might be that academic chairpersons do not possess the necessary conflict management skills, as highlighted in a study by Stanley and Algert (2007, 50). Conflict also seems to be one of the main contributors to job dissatisfaction of academic chairpersons, as Gmelch found in a study (as cited in Stanley and Algert 2007, 51) among academic chairpersons; conflict alone contributed to 60 per cent of their dissatisfaction.

Other human resource activities that seem to pose difficulty to chairpersons as indicated in their remarks revolving around the time and effort required for aspects such as recruitment, motivation and the coaching of personnel. This is expressed in the following comments:

One of the more challenging tasks for me is to find and appoint people in the light of the affirmative action policy and a policy that requires academics to be bilingual. When you do however find people, the salary is not enough and the net result is that you end up with people that you don't 
really want, in an attempt to change your personnel composition.

I have a lot of youngsters in my department who are busy building their careers, but in the absence of senior people in the department I have to fulfil this role, which in many cases doubles your tasks and responsibilities.

Gmelch and Burns (1993, 265) and Graham and Benoit (2004, 3, 5) substantiate the aforementioned when they state that one of the biggest challenges for chairs is the amount of time they need to spend solving personnel problems and issues arising from hiring and supporting faculty (be it in the form of coaching and counselling) to managing and mediating conflicts that arise between staff members, and that those issues are particularly stressful for those new in the role.

As illustrated in the literature, one of the main reasons why chairpersons find the administrative/management/leadership role so challenging is that they very often lack the necessary knowledge, skills and experience for managing an academic department and that they have not been adequately prepared for this role. Various comments highlight this particular issue, for example:

I’ve got thrown into the job, without any basic management experience or training.

We are trained in our respective fields, but we are not trained to be managers; you can be good in your particular field, but it does not make you a good line manager.

I came here and I knew nothing about how academia works and there was no one to help me. After a month I was elected to be the chair of the department and I was told to manage. I had no idea how the budget works, nor had I any idea how HR worked. There was no one who was prepared to talk or help me understand the various systems and functions around this position. So it's been an incredibly difficult period. And then on top of that you're still expected to perform.

This is further exacerbated by a system that seems to set academic chairpersons up for failure, since many institutions of higher learning still primarily utilise academic performance and research experience as the main performance indicators when appointing chairpersons, although the role requires a wealth of managerial skills and experience. The following comment highlights this issue:

This is what I don't understand: 'they' feel that the person who runs a department should have a specific academic and research qualification and standing.

I remember even when I applied for the position; they would look at you as an academic - what is your research output? What is this, what is that? Not as, what is your competency as a manager. 
The above statements are endorsed by Gmelch and Burns $(1994,79)$, Lyons $(2008,135)$ and Hecht et al. (1999, 5), who state that institutions continue to fill academic chairperson positions with strong teachers and researchers who must assume a role that requires complex and challenging administrative and managerial skills and knowledge, as well as leadership competencies. They very often do not consider whether the person possesses or demonstrates the skills necessary for the administrative/management/leadership part of this role.

It is very unlikely, according to the authors of this article, that chairpersons would be required to demonstrate skills in managing conflict, marketing and recruitment of staff before having been appointed as chairs. This notion is supported by Aziz et al. (2005, 572), Buffone (2009, 21), Ferren and Stanton (as cited in Lyons, 2008, 135), Potgieter and Coetzee (2010, 9) and Wescott (2000, 3), who assert that chairpersons are rarely prepared for this position and that they are often from disciplines that are not familiar with administration, management or leadership. The gravity of this is matter is highlighted by Aziz et al. (2005, 572), who point out that, despite the fact that this matter has been discussed by researchers for well over 30 years, that minimal progress has been made in this regard.

\section{Administration}

The challenge of finding a balance between the academic and management roles is, in the absence of the necessary skills, knowledge and preparation for their management role, intensified by an ever-increasing administrative load that academic chairpersons have to contend with. Participants revealed this challenge in comments such as: 'There is no infrastructure to support you', 'The administrative load gets dumped onto me' and 'There is so much administration and it seems to get worse'. These experiences are substantiated by Wescott (2000, 2, 4),

\section{Fundraising}

One of the more serious examples, when considering additional responsibilities, are some chairs who articulated that they have to 'constantly generate more money and obtain grants and funds' over and above their other responsibilities 'in an attempt to keep this place afloat - literally from year to year'. Their experience is supported by Floyd (2012, 273) and Penny (as cited in Lyons 2008, 54) who state that securing funds for departments are one of the primary responsibilities of an academic chairperson. Comments such as: 'This is most probably the thing that keeps me the most awake at night - fundraising, as our unit is primarily funded from outside funds' and 'I have this pressure to raise funds the whole time', bear further evidence of 
this particular challenge.

\section{Decision-making power}

The complexity and resulting challenges of this role are furthermore highlighted by comments made by chairpersons that they are not 'empowered to make decisions' and that they have 'little to no decision-making power'. This is endorsed by statements of chairpersons who indicated that they need to manage by 'relationship and goodwill' and supported by Hecht et al. (1999, 12-13, 16), Lyons $(2008,79)$ and King $(1997,212)$. The challenge of not having sufficient power is highlighted by Lyons (2008, 76, 78), who refer to research by Anderson, Hubell and Homer indicating that chairpersons have great responsibility, but little power. According to these authors, chairpersons rank lowest in power amongst administrators, even lower than faculty members. Lyons also refers to Tucker, who has shown that chairpersons seem to have more perceived authority than real formal authority.

\section{Contextual challenges (Theme 2)}

The findings of this study illustrate how contextual realities affect the already challenging role of an academic chair and that this role does not function in isolation - something previous research did not consider explicitly, mainly due to the limitations of the research approach and resulting data-gathering methodologies employed. According to Berdrow (2010, 500), the role of academic chair cannot be considered in isolation from the context in which the individual chair functions. The following contextual challenges were found to affect the role of a chairperson in this institution: institutional culture, remuneration and the student profile. Each of these challenges will be discussed in the following paragraphs.

\section{Institutional culture}

One gains more insight into how taxing the role of academic chair is when considering the culture of the particular institution in which these chairpersons, and by implication this role, function. Some of the responses (and only a few have been reproduced here) depict an organisational culture characterised by:

Suspicion: 'There is not such a thing as telling something to someone in confidentiality, there is not such a thing as a secret'.

Distrust: 'Don't delete any emails or any other any evidence that you need to use when people are making accusations against you', 'At the risk of also being excommunicated, the vice-chancellor made some pretty vicious comments to staff members about us being not very 
good academics and staff, and that we're part of the problem. And that is really part of the toxicity. I am not sure if he's aware of it and I am not sure if anything is really being done to deal with it.'

Unwritten rules: 'There are a lot of unwritten rules', 'If you don't understand the politics in the university you won't be able to function as a departmental chairperson' and 'You need to know when to keep quiet, otherwise you'll be crushed'.

Not feeling valued: 'I think it has been mentioned a couple of times, the total disrespect for the whole structure, it really makes you question whether you have a role to play'.

A disregard of line management by the vice-chancellor and a disconnection between top management and academic chairpersons: 'The people in those top positions have no idea what's happening on the "ground"'.

The divide between top management and academics, where the chairperson has to manage this relationship and occupy the classic person-in-the-middle role, is echoed by the following statement:

You've touched on something that's really important here, we have this 'culture' [which actually refers to top management in this context] that sets these incredible performance standards by people who have got the tenure. All of my staff looked at it and said, none of us will ever get promoted. There is no way that we are ever going to be able to reach this, not with the kind of teaching loads we have and the amount of research that we need to publish. This is really making people very despondent.

\section{Remuneration}

The poor financial reward associated with the role of an academic chair poses another serious challenge for chairpersons as some of them commented that, 'there is no real financial gain for becoming a chairperson' and that this is also one of the main reasons why people do not consider or apply for this position, as articulated in comments such as 'When you start to talk about the little money you earn in this position, people tend to look away' and 'I mean, you will actually laugh if you know what I get in a month for having all this responsibility'.

\section{Student profile}

It seems that some of the challenges faced by academic chairs stem from the lower quality and higher number of students that are accommodated at higher education institutions in South Africa, which indirectly affects their role, as illustrated in the following comments: 'The problems these days are that we have many more students in our offices and it is normally the “sick, lame and lazy”,' and 'From 2004 our student numbers doubled and we didn't get one 
extra staff member and we are still exactly the same amount of staff members, but with almost double the amount of undergraduate students'. This issue is corroborated by Lyons (2008, 49, 50), who indicates that by 2008 already 47000 foreign students alone have been enrolled at institutions of higher learning in South Africa. Academic chairpersons further have to manage the demographic profiles of students and staff members who have different schooling backgrounds, languages and cultural backgrounds.

\section{Consequences postulated as challenges (Theme 3)}

There are various consequences (postulated as challenges) to becoming an academic chair that have shown up in comments related to the negative effect that this position has on incumbents' personal health and well-being and their academic careers.

\section{Personal health and academic career}

Occupying this role seems to come with certain consequences for those who are willing to take it on. For example, chairpersons described how they 'don't know how to switch off anymore' and that they 'don't cope anymore and that this is the real problem'. One other participant indicated how she has 'experienced burnout four times in the last eight years', while another mentioned that he 'struggles to sleep and that this sometimes leads to panic attacks at night'.

Over and above all the challenges chairpersons face as depicted in the preceding findings and literature, they also run the risk of sacrificing or stalling their own academic careers when taking up this role, as portrayed in comments such as, 'If I look back, I realise that I've really damaged my academic career and I've deferred my academic career with between 5-6 years' and 'No one wants to take over from me, everyone who I've approached tells me that it is not worth it'. These findings are corroborated by Gmelch and Miskin $(1993,7)$ and Gmelch and Burns $(1993,265)$ who show in research that 86 per cent of chairpersons significantly reduce their scholarly activities, and for some their scholarship virtually ceases. This state of affairs is confirmed by Floyd $(2012,273)$ and King $(1997,211)$ who state that a term as academic chairperson actually hinders a person's academic career (research and teaching), as well as the activities that enable academics to obtain promotions and collegial recognition (academic survival). Research by Wolverton, Gmelch, Wolverton and Sarros (as cited in Lyons 2008, 140) found in a study of 534 chairpersons that insufficient time to stay current in their academic disciplines was considered the most stressful aspect of their role.

\section{Final remarks and questions that arise from this research}


When reflecting on the challenges identified and grouped together in Theme 1, the findings of this study seem to reveal that the major challenge for academic chairpersons stems from trying to balance their academic and management/administrative/leadership role (the Janus effect). But it is the various aspects of the latter role (management requirements, the lack of management skills, experience and knowledge, the ever-increasing administrative load, increasing responsibilities to ensure financial sustainability in the absence of the necessary decision-making power) that cause the most significant challenges, and not so much their role as academics.

Further findings as illustrated in Theme 2 leads one to realise that it is not only the role in itself that is challenging, but that there may be other contextual factors, beyond the boundaries of this role, affecting it. Aspects highlighted in this study are a 'problematic' institutional culture, poor remuneration and a higher number of lower quality students that chairpersons have to contend with.

Theme 3 (consequences portrayed as challenges), illustrates how occupying this role comes with certain consequences, in that chairpersons sacrifice themselves as they pay the price: poorer physical and emotional health and an academic career that loses its momentum.

The findings of this study exposes a serious threat to the effective functioning of the institution where this research had been conducted, and, possibly, to other institutions of higher learning, as more chairpersons and those considering this position will come to realise that it is not always sensible to take up this role, given all the realities depicted in these findings and the literature.

The question that still remains unanswered in the literature today is why, after more than two decades of research and once again illustrated by the findings of the current study, do institutions of higher learning, and by implication administrators, still continue with practices that force these two roles into one (the Janus effect), when it very clearly seems not to be a workable or sustainable.

What is it that the administrators of institutions are not aware of? Or are they so oblivious to the magnitude of roles and responsibilities attached to the role of academic chair, the contextual factors affecting this role and the resulting consequences that they just do not care enough to reconceptualise this role? Could it be that they do not have the know-how to go about reconceptualising this role? Or does their apathy reflect their stance as institutions - that they have little regard for the people in the role of academic chair when literature has frequently shown in the past that this role is not sustainable in its current format? How acceptable is the possibility that academic chairpersons are viewed and treated as objects by institutions, while 
literature shows that they occupy one of the most important leadership roles at an institution of higher learning, and that chairpersons make up to 80 per cent of all the administrative decisions? Could it be that institutions try to soothe their conscience by offering its support to chairpersons in the form of training, when in fact training and preparation may not fully address the core problem? The inappropriateness of training alone as a way to support and prepare academic chairpersons is highlighted by the following remarks:

If experience is such an important teacher, and the motivation to lead is rooted in one's past, and leadership skills are indeed so complex and related to one's work and past, what role can training hope to play? (Conger (1992) cited in Gmelch 2004, 74).

If it takes seven to fourteen years to achieve expertise in an academic discipline, why do we assume we can create academic leaders with a weekend seminar? (Gmelch 2004, 75).

\section{CONCLUSION}

The purpose of this article was to gain a deeper understanding of the multidimensional nature and complexity of the challenges that academic chairpersons appointed at institutions of higher learning experience. A qualitative research approach, involving a focus group of 24 academic chairpersons, was followed to gain a comprehensive understanding of the phenomenon under investigation.

The findings of the research suggest that academic chairpersons are inundated with multiple responsibilities. Tasks from two opposing roles, that of academic and that of manager, are forced into one role, resulting in various serious challenges for incumbents, as depicted in the findings of this research. The findings of this study and the cited literature paint a bleak picture of the sustainability of the role of an academic chairperson if it is not completely reconceptualised and reconstructed.

\section{Recommendations}

Given the complexity and multidimensional nature of the role of academic chair and the various tasks and responsibilities associated with it, the current researchers suggest that this role be redesigned - as recommended by Gmelch in 2004 already. It is clear from the experiences of academic chairpersons in this study that they are often faced with tasks and responsibilities associated with those of human resources, finances and marketing divisions; aspects that they are often not trained to manage or carry out. The technical experts in and custodians of these fields normally reside in the administration of higher education institutions. It is therefore 
recommended that both administrators and academic chairpersons initiate processes and activities to ensure stronger collaboration between those two groups.

If institutions of higher education, however, decide to continue with the practice of forcing these two roles into one, they should at least ensure that all prospective and current chairpersons have the necessary support and that they are prepared for their role. This could be achieved by making chairpersons aware of all the realities mentioned in the findings of this study, and by providing them with the necessary training to equip them to deal with the administrative/managerial/leadership and contextual challenges and consequences inherent to this multi-dimensional role. Chairpersons cannot be expected to be successful without sufficient preparation and support. Support may take on the form of extensive general administrative support, compulsory sabbatical leave in order for them to pursue their research activities, or additional research assistants to assist them with their research activities.

\section{Future research}

From an academic perspective, the research findings contribute to the literature by providing a more in-depth and integrated overview of the possible challenges faced by chairpersons at institutions of higher learning. Contextual challenges affecting this role are also indicated.

This study, however, included only chairpersons from one institution of higher learning in South Africa. It would be advisable to replicate this study at other such South African institutions in order to determine whether there are any other challenges not identified in this particular study. It would also be valuable to determine why academic chairpersons step into this position in the first place, given the realities, and how they come to cope with the demands of this position, as a way to bring about better support for future chairpersons.

\section{REFERENCES}

Aziz, S., M. E. Mullins, W.K. Balzer, E. Grauer, J. L. Burnfield, M. A. Lodato and M. A. CohenPowless. 2005. Understanding the training needs of department chairs. Studies in Higher Education 30(5): 571-593.

Bazeley, P. 2013. Qualitative data analysis. London: Sage Publishing.

Berdrow, I. 2010. King among kings: Understanding the role and responsibilities of the department chair in higher education. Educational Management Administration \& Leadership 38(4): 499-514.

Berg, B. L. 2001. Qualitative research methods. $4^{\text {th }}$ edition. Boston: Pearson Education.

Boateng, W. 2012. Evaluating the efficacy of focus group discussion (FGD) in qualitative social research. International Journal of Business and Social Science 3(7): 54-77.

Braun, V. and V. Clarke. 2006. Using thematic analysis in psychology. Qualitative research in Psychology 3: 77-101. 
Breverton, P. and L. Millward. 2004. Organisational research methods. A guide for students and researchers. London: Sage.

Brynman, A. 2009. Research and development series: Effective leadership in higher education. London: Leadership Foundation for Higher Education.

Buffone, N. 2009. Leadership continuity: Enhancing the cycle of leadership in academic departments. Unpublished doctoral thesis, University of Massachusetts, Boston.

Carroll, J. B. and M. Wolverton. 2004. Who becomes a chair? New Directions for Higher Education 126: 3-10.

Czech, K. and G. L. Forward. 2010. Leader communication: Faculty perceptions of the departmental chair. Communications Quarterly 58(4): 431-457.

De Vos, A. S., H. Strydom, C. B. Fouché and C. S. L. Delport. 2002. Research at grass roots. For the social sciences and human service professions. Pretoria: Van Schaik.

Floyd, A. 2012. 'Turning points': The personal and professional circumstances that lead academics to become middle managers. Educational Management Administration \& Leadership 40(2): 272284.

Gmelch, W. H. 2004. The department chair's balancing acts. New Directions for Higher Education (Special Issue) 126: 1-92.

Gmelch, W. H. and J. S. Burns. 1993. The cost of academic leadership: Department chair stress. Innovative Higher Education 17(4): 259-270.

Gmelch, W. H. and J. S. Burns. 1994. Sources of stress for academic department chairpersons. Journal of Educational Administration 32(1): 79-94.

Gmelch, W. H. and V. D. Miskin. 1993. Understanding the challenges of department chairs. Leadership skills for departmental chairs. Bolton: MA.

Graham, S. and P. Benoit. 2004. Constructing the role of department chair. Department chair online resource centre, 1-8. http://www2.acenet.edu/resources/chairs/docs/Graham_Constructing.pdf (accessed 14 Dec0ember 2012).

Hecht, I. W. D., M. L. Higgerson, W. H. Gmelch and A. Tucker. 1999. The department chair as academic leader. Phoenix: Oryx Press.

Hecht, I. W. D. 2004. The professional development of department chairs. Journal for New Directions for Higher Education Summer 126: 27-44.

Hirschhorn, L. 1997. Reworking authority. Leading and following in the post-modern organisation. London: MIT.

King, P. E. 1997. Surviving an appointment as department chair. Journal of the Association for Communication Administration 3: 211-217.

Kreuger, R. A. and M. A. Casey. 2009. Focus groups: A practical guide for applied research. $4^{\text {th }}$ edition. Thousand Oaks, CA: Sage.

London, C. 2011. Measuring how the head of department measures up: Development of an evaluation framework for the head of department role. Quality in Higher Education 17(1): 37-51.

Lyons, M. 2008. The leadership role of head of department at university. Unpublished doctoral thesis, University of Pretoria, Pretoria.

Onwuegbuzie, A. J., W. B. Dickinson, N. L. Leech and A. G. Zoran. 2009. A qualitative framework for collecting and analyzing data in focus group research. International Journal of Qualitative Methods 8(3): 1-21.

Potgieter, I., J. Basson and M. Coetzee. 2011. Management competencies for the development of heads of department in the higher education context: A literature overview. South African Journal of Labour Relations 35(1): 81-103.

Potgieter, I. L. and M. Coetzee. 2010. Management competencies in higher education: Perceived job 
importance in relation to level of training required. SA Tydskrif vir Menslikehulpbronbestuur 8(1): $1-10$.

Rowley, D. J. and H. Sherman. 2003. The special challenges of academic leadership. Management Decision 41(10): 1058-1063.

Sotirakou, T. 2004. Coping with conflict within the entrepreneurial university: Threat of challenge for heads of departments in the UK higher education context. International Review of Administrative Sciences 70(2): 345-372.

Spiller, D. 2010. Language and academic leadership: Exploring and evaluating the narratives. Higher Education Research \& Development 29(6): 679-692.

Stanley, C. A. and N. E. Algert. 2007. An exploratory study of the conflict management style of department heads in a research university setting. Innovative Higher Education 32: 49-65.

Stewart, D. W., P. N. Shamdasani and D. W. Rook. 2007. Focus groups: Theory and practice. $2^{\text {nd }}$ edition. London: Sage Publications.

Terre Blanche, M., K. Durrheim and D. Painter. 2006. Research in practice. Applied methods for the social sciences. Cape Town: UCT Press.

Wescott, J. W. 2000. Perspectives from a new departmental chair. The Journal of Technology Studies, 26(2) Summer/Fall. http://scholar.lib.vt.edu/ejournals/JOTS/Summer-Fall-2000/wescott.html (accessed 10 December 2012).

Wilkinson, S. 2011. Analysing focus group data. In Qualitative Research, ed. D. Silverman, 168-184. $3^{\text {rd }}$ edition. Los Angeles: Sage.

Wolverton, M., R. Ackerman and S. Holt. 2005. Preparing for leadership: What academic department chairs need to know. Journal of Higher Education Policy and Management 27(2): 227-238.

Wolverton, M., W. H. Gmelch, M. L. Wolverton and J. C. Sarros. 1999. Stress in academic leadership: U.S. and Australian department chairs/heads. The Review of Higher Education 22(2): 165-185.

Zaharlick, A. 1992. Ethnography in anthropology and its value for education. Theory into Practice 31(2): 116-125. 